\title{
Water-Free Titania-Bronze Thin Films with Superfast Lithium-Ion Transport
}

\author{
Kui Zhang, Michael B. Katz, Baihai Li, Sung Joo Kim, Xianfeng Du, Xiaoguang Hao, \\ Jacob R. Jokisaari, Shuyi Zhang, George W. Graham, Anton Van der Ven, \\ Bart M. Bartlett, and Xiaoging Pan**
}

Energy storage materials with high capacity and rapid charge/ discharge rates hold the key to the next breakthrough in lithium-ion batteries (LIBs), expanding the application to high power systems such as electric vehicles.[1] The bronze polymorph of titanium dioxide $\left(\mathrm{TiO}_{2}-\mathrm{B}\right)$ is an excellent candidate due to its open structure ${ }^{[2]}$ and fast lithium-ion transport via a pseudocapacitive Faradaic process, leveraging ultrahigh discharge rates comparable to those of supercapacitors while maintaining the advantage of storing energy in the bulk. ${ }^{[3,4]}$ However, the existing powder/slurry form prepared by hydrothermal methods ${ }^{[5-12]}$ cannot provide clear insight into its fundamental characteristics, due to the limited purity, the randomized crystal orientation, and the unavoidable presence of lattice water in its structure. ${ }^{[13]}$ Here we report the discovery of a waterless process to synthesize hetero-epitaxial crystalline thin films of $\mathrm{TiO}_{2}-\mathrm{B}$ using pulsed laser deposition (PLD) onto a related material, $\mathrm{Ca}: \mathrm{TiO}_{2}-\mathrm{B}\left(\mathrm{CaTi}_{5} \mathrm{O}_{11}\right)$, which serves as a template. By aligning the more open channels to out-of-plane directions, extremely high rates of lithium-ion transport-up to $600 C$, where a rate of $n C$ corresponds to a full discharge in $1 / n$ hours - with extraordinary structural stability can be achieved. Our results provide the basic knowledge needed to realize and utilize $\mathrm{TiO}_{2}$ - $\mathrm{B}$ single crystals, while also supporting theoretical studies with determinate experimental data. As the methods and equipment required are readily accessible to the extended research community, we anticipate our report may stimulate further studies on and applications of these materials, which are attractive in realms that extend beyond LIBs, including solar energy conversion, thermoelectrics, photocatalysis, water splitting, and sensors. ${ }^{[14]}$

K. Zhang, Dr. M. B. Katz, ${ }^{[+]}$Dr. B. H. Li, S. J. Kim,

Dr. X. F. Du, J. R. Jokisaari, S. Y. Zhang,

Prof. G. W. Graham, Prof. A. Van der Ven, ${ }^{[++]}$

Prof. X. Q. Pan

Department of Materials Science and Engineering

University of Michigan

Ann Arbor, MI 48109, USA

E-mail: panx@umich.edu

X. G. Hao, Prof. B. M. Bartlett

Department of Chemistry

University of Michigan

Ann Arbor, MI 48109, USA

${ }^{[+]}$Present address:US Naval Research Laboratory, 4555 Overlook Ave. SW, Washington, DC 20375, USA

${ }^{[++]}$Present address: Materials Department, University of California Santa Barbara, Santa Barbara, CA 93106, USA

DOI: 10.1002/adma.201401757
$\mathrm{TiO}_{2}$ has been extensively investigated as an anode material for the LIB due to its low cost, minimal environmental impact, structural stability, high theoretical capacity $\left(335 \mathrm{~mA} \mathrm{~h} \mathrm{~g}^{-1}\right)$, and inherent safety (a buffer $>1.5 \mathrm{~V}$ before lithium plating). ${ }^{[15,16]}$ Fast lithium storage has been demonstrated in anatase, rutile, and $\mathrm{Li}_{4} \mathrm{Ti}_{5} \mathrm{O}_{12}$ nanostructures. ${ }^{[17-20]}$ Although known to have advantages over anatase or rutile, high-quality bronze-phase $\mathrm{TiO}_{2}$-B specimens that demonstrate good electrochemical properties thus far have exclusively been nano-structured powders prepared by hydrothermal methods, ${ }^{[10,11,13,21-24]}$ as first synthesized in 1980. ${ }^{[2]}$ Being a metastable phase, compounded by the fact that $\mathrm{TiO}_{2}$-anatase, which rarely fully reacts, ${ }^{[25]}$ is often used as a precursor in existing synthesis methods, phase-pure $\mathrm{TiO}_{2}-\mathrm{B}$ has been extremely difficult to obtain, obscuring the interpretation of property-testing results. In addition, removal of all $\mathrm{H}_{2} \mathrm{O}$, which could interfere with $\mathrm{Li}^{+}$transport, from the final product proves to be difficult, and recent studies have suggested that $\mathrm{H}_{2} \mathrm{O}$ may even be needed to keep it from collapsing into anatase upon aggressive heating. ${ }^{[13,26,27]}$ In this work, we discovered that $\mathrm{Ca}$ can stabilize the bronze structure, forming a variant phase $\mathrm{CaTi}_{5} \mathrm{O}_{11}$, and by using it as a template layer, have successfully synthesized epitaxial $\mathrm{TiO}_{2}$-B single-crystalline thin films by PLD, a completely waterless process. Significant enhancement in the battery performance is achieved by exploiting the epitaxial relationship with the substrate. The ability to accurately control the crystal orientation will be especially beneficial to studies focused on surface states, such as in photocatalysis and photovoltaic applications.

The $\mathrm{CaTi}_{5} \mathrm{O}_{11}$ stable phase was observed in atomic-resolution high-angle annular dark-field (HAADF) scanning transmission electron microscopy (STEM) images, according to which we have built the geometric model and then performed first-principles optimization by PW91 functional implemented in VASP (Vienna ab-initio Simulation Package). ${ }^{[28,29]}$ Our more accurate $\mathrm{HSE06}$ method ${ }^{[30]}$ calculations indicate that $\mathrm{CaTi}_{5} \mathrm{O}_{11}$-or $\mathrm{Ca}_{4} \mathrm{Ti}_{20} \mathrm{O}_{44}$ in a unit cell-is an orthorhombic structure with lattice constants of $a=12.1702 \AA, b=3.8013 \AA, c=17.9841 \AA$, $\alpha=\beta=\gamma=90^{\circ}$ (see Supporting Information (SI): Table S1 for atom positions). Its crystal structure projected along three crystallographic directions is compared with the regular $\mathrm{TiO}_{2}-\mathrm{B}$ structure in Figure 1. The PLD target recipe and the growth conditions, which are detailed in the Experimental Section, have been optimized to produce a high-quality $\mathrm{CaTi}_{5} \mathrm{O}_{11}$ thin film deposited onto a (100) $\mathrm{SrTiO}_{3}$ substrate. Figure 2a shows the $\theta-2 \theta$ X-ray diffraction (XRD) pattern for an epitaxial (001) thin film of the $\mathrm{CaTi}_{5} \mathrm{O}_{11}$ phase. A HAADF STEM image taken along the $b$ direction of the structure is displayed in Figure $2 b$, 


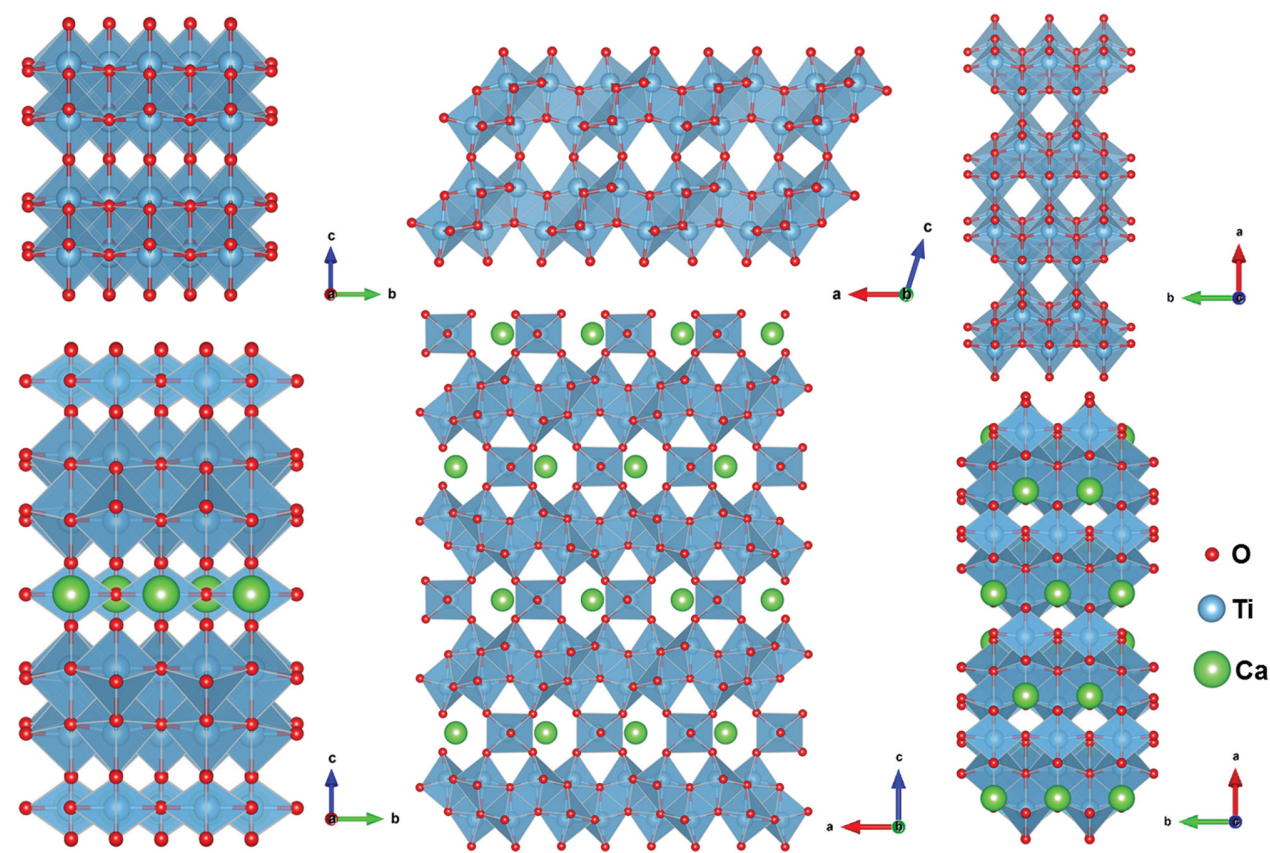

Figure 1. Crystal structures of regular $\mathrm{TiO}_{2}-\mathrm{B}$ (top row) and $\mathrm{Ca}: \mathrm{TiO}_{2}-\mathrm{B}\left(\mathrm{CaTi}_{5} \mathrm{O}_{11}\right.$, bottom row) projected along [100], [010] and [001] directions, respectively. These drawings were produced using VESTA.
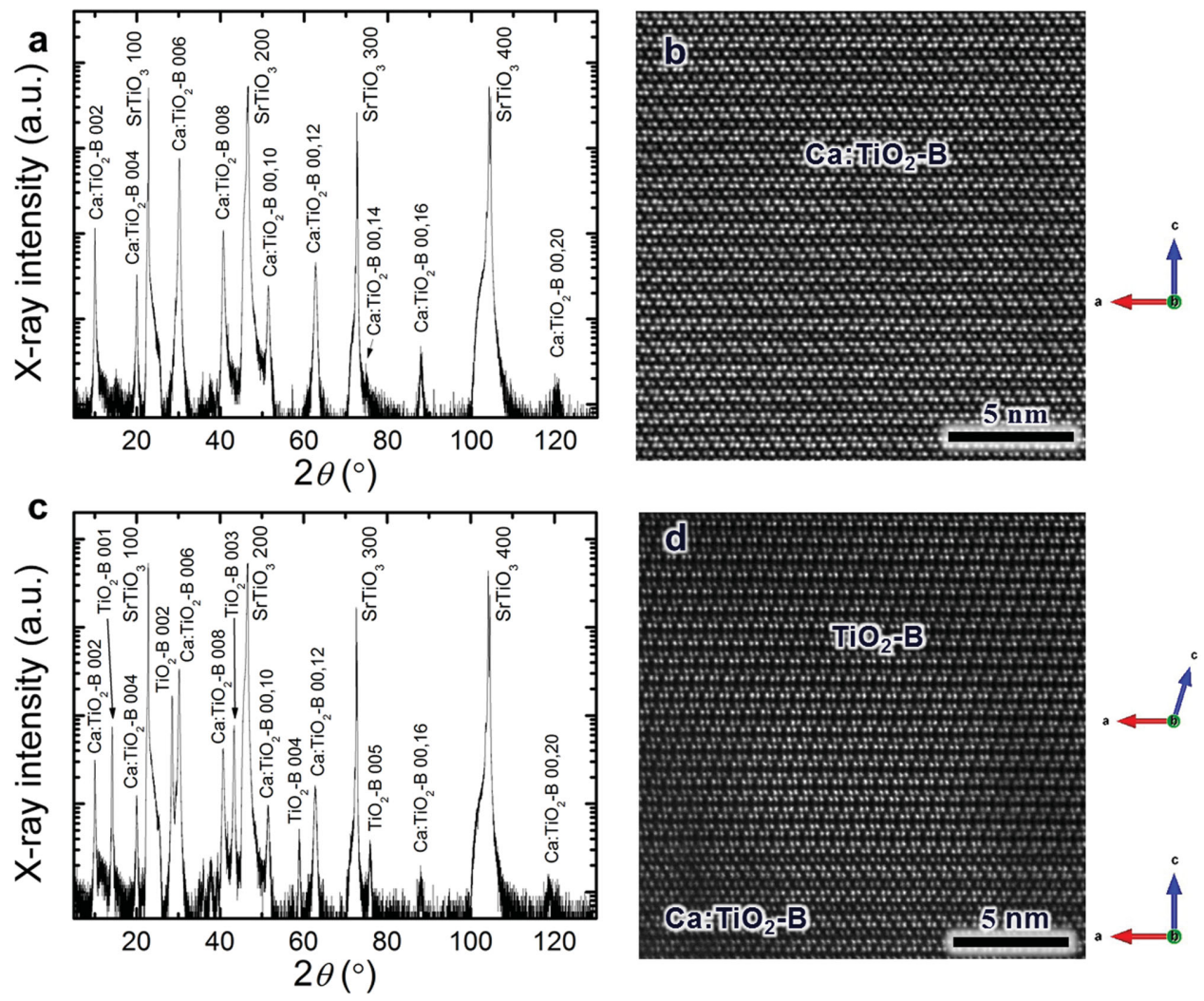

Figure 2. Structural characterization of $\mathrm{Ca}: \mathrm{TiO}_{2}-\mathrm{B}$ and regular $\mathrm{TiO}_{2}-\mathrm{B}$. a) XRD pattern of a $\mathrm{Ca}: \mathrm{TiO}_{2}-\mathrm{B}$ thin film grown on a (100) $\mathrm{SrTiO}$ substrate at $800^{\circ} \mathrm{C}$ by PLD. The hetero-epitaxial relationship is [100](001) $\mathrm{Ca:TiO2-B}_{\mathrm{B}} \mathrm{ll}[100](001)_{\mathrm{SrTTO}_{\mathrm{O}}}$. b) HAADF STEM image of the Ca:TiO ${ }_{2}-\mathrm{B}$ phase. C) XRD pattern of a regular $\mathrm{TiO}_{2}-\mathrm{B}$ thin film grown on top of a thin $\mathrm{Ca}: \mathrm{TiO}_{2}-\mathrm{B}$ template layer on a (100) $\mathrm{SrTiO}_{3}$ substrate under the same PLD conditions. d) HAADF STEM image of the dual-layer structure. 
showing an interesting layered, zigzag pattern where every inserted layer of alternating $\mathrm{Ti}$ and $\mathrm{Ca}$ atoms flips the stacking direction of the next two layers of $\mathrm{Ti}$ atoms above it, consistent with the atomic model in Figure 1. Since it is a variant of the $\mathrm{TiO}_{2}$-B structure with extra Ca layers and superlattice twinning, we designate the phase as $\mathrm{Ca}: \mathrm{TiO}_{2}$-B.

We have found that this structure can be used as a template layer to grow (001) regular $\mathrm{TiO}_{2}$ - $\mathrm{B}$ thin films: direct deposition of pure $\mathrm{TiO}_{2}$ on $\mathrm{SrTiO}_{3}$ substrates usually results in the anatase phase, ${ }^{[31]}$ but highly crystalline $\mathrm{TiO}_{2}$ - $\mathrm{B}$ forms on the $a-b$ plane of a Ca: $\mathrm{TiO}_{2}$-B layer (SI: Figure S1) by ablating a pure $\mathrm{TiO}_{2}$ target under the same growth conditions, mainly because of the nearperfect lattice match between the two phases. The structure parameters of our $\mathrm{TiO}_{2}$-B films are in good agreement with values in the literature. ${ }^{[32,33]}$ The thinnest template layer we have used so far was $10 \mathrm{~nm}$, and no degradation of the $\mathrm{TiO}_{2}$-B crystalline quality was observed. Figure $2 \mathrm{c}$ and $2 \mathrm{~d}$ show the $\theta-2 \theta$ XRD pattern and the HAADF image, respectively, of the dual-layer structure. The theoretical densities of $\mathrm{Ca}: \mathrm{TiO}_{2}-\mathrm{B}$ and $\mathrm{TiO}_{2}$ - $\mathrm{B}$ are determined to be 3.637 and $3.616 \mathrm{~g} \mathrm{~cm}^{-3}$, respectively, approximately $7 \%$ lower than that of anatase.

For both the $\mathrm{Ca}: \mathrm{TiO}_{2}-\mathrm{B}$ and $\mathrm{TiO}_{2}-\mathrm{B}$ structures, $\mathrm{Li}^{+}$access into the crystal is expected to be easier in the $a-b$ plane, i.e., through the well-aligned channels along the $a$-axis between layers of atoms (Figure 1 and $2 \mathrm{~b}, \mathrm{~d}$ ) as well as the possibly even faster channels along the $b$-axis, ${ }^{[3,34-36]}$ than in the perpendicular direction. Therefore, it will be preferable to have these open channels exposed at the film surface to increase the rates of lithium-ion transport, which in principle can be achieved by utilizing substrates with a different orientation. Figure $3 \mathrm{~b}$ shows the HAADF image of a $\mathrm{Ca}: \mathrm{TiO}_{2}$-B film deposited on a (110)
$\mathrm{SrTiO}_{3}$ substrate under the same growth conditions as above. Instead of being parallel to the surface, the $a-b$ planes are now inclined, with channels along the $a$ - and $b$-axes reaching the surface. Figure 3a clearly displays a region near the boundary between two such grains, where one grain (right) has channels parallel to the $a$-axis running to the surface, and another grain (left) is rotated about the $a-b$ plane normal having channels parallel to the $b$-axis running to the surface. Figure $3 b$ shows the polycrystalline nature of the film. It was found, however, that such a $\mathrm{Ca}: \mathrm{TiO}_{2}$-B film does not serve as a good template layer for the subsequent growth of uniform $\mathrm{TiO}_{2}$-B on top.

To study their electrochemical properties, the thin films were assembled in half-cells with metallic Li as counter electrode. The experimental designs and procedures are detailed in SI (Figure S2-S6). ${ }^{[37]}$ For $\mathrm{Ca}^{-} \mathrm{TiO}_{2}-\mathrm{B}$, assuming $5 \mathrm{Li}^{+}$are intercalated per $\mathrm{CaTi}_{5} \mathrm{O}_{11}$ formula unit (making all $\mathrm{Ti} 3+$ ), its theoretical capacity is estimated to be $294 \mathrm{~mA} \mathrm{~h} \mathrm{~g}^{-1}$. For simplicity and comparison with $\mathrm{TiO}_{2}-\mathrm{B}$, we define in this paper $1 \mathrm{C}$ $=335 \mathrm{~mA} \mathrm{~g}^{-1}$. Superior charge/discharge rate capability was observed in the Ca: $\mathrm{TiO}_{2}$-B film grown on (110) $\mathrm{SrTiO}_{3}$ with open channels extending to the surface. Starting at $1 C$, the battery half-cell was charged and discharged between 1 and $3 \mathrm{~V}$ for 50 cycles at each of several rates up to an extreme of $600 \mathrm{C}$, ending again at $1 \mathrm{C}$ immediately following the last cycle at the highest rate for an additional 20 cycles to examine the structural stability. Figure $3 \mathrm{~d}$ shows the voltage curves of the $5^{\text {th }}$ cycle at each rate. At $1 C$, the film discharges to a specific capacity of $293 \mathrm{~mA} \mathrm{~h} \mathrm{~g}^{-1}$, over $99.6 \%$ of the theoretical capacity. The capacity reduced to $248 \mathrm{~mA} \mathrm{~h} \mathrm{~g}^{-1}$ at $10 \mathrm{C}, 61.4 \mathrm{~mA} \mathrm{~h} \mathrm{~g}^{-1}$ at $120 \mathrm{C}$, and $28.8 \mathrm{~mA} \mathrm{~h} \mathrm{~g}^{-1}$ at $600 \mathrm{C}$, likely because only a fraction of the film close to the surface and the current collector
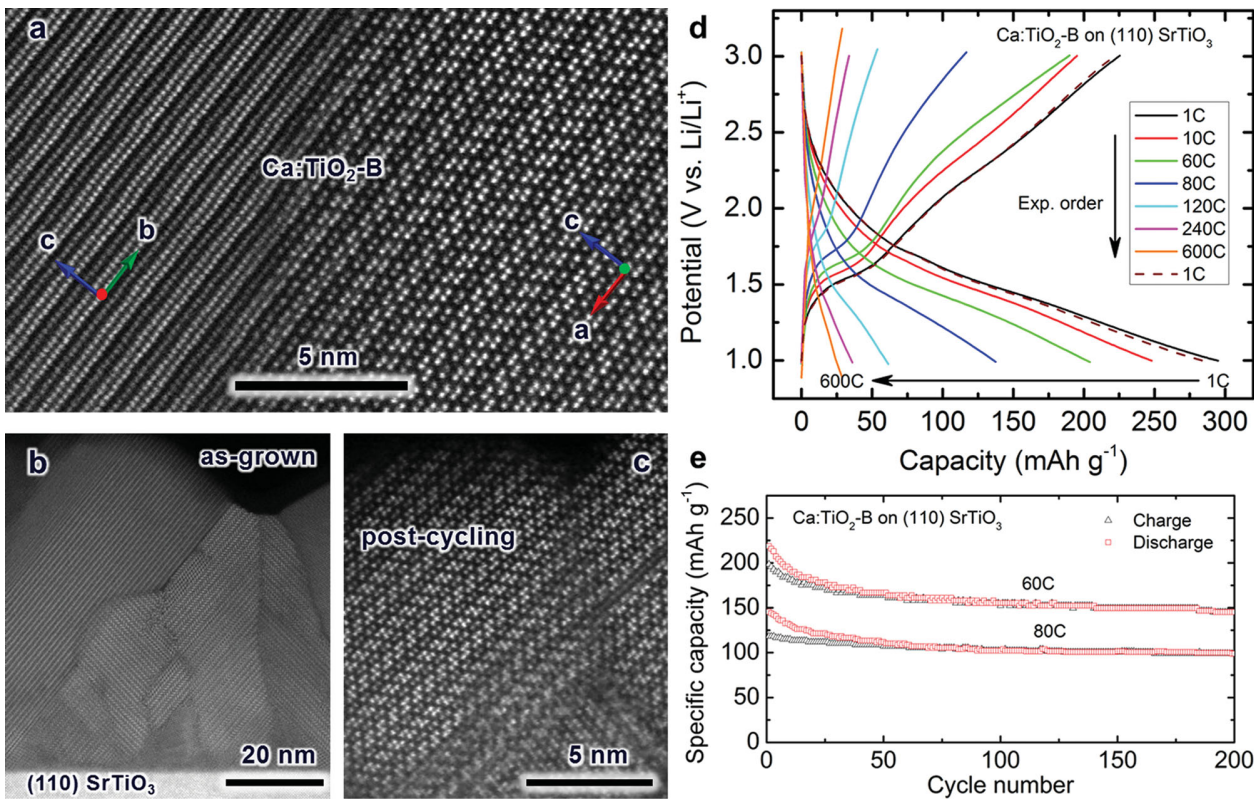

Figure 3. Structure and electrochemical performance of an inclined $\mathrm{Ca}: \mathrm{TiO}_{2}-\mathrm{B}$ film grown on a (110) $\mathrm{SrTiO}_{3}$ substrate. a) HAADF STEM image of a region near a grain boundary. b) Lower-magnification STEM image showing the polycrystalline nature of the film. Different grains have channels along different directions exposed at the surface. c) HAADF STEM image showing a region near the surface after aggressive cycling for more than 60 days. No significant structural degradation, either on the surface or in the film, was observed. d) Charge-discharge voltage profiles of the $5^{\text {th }}$ cycle at each current rate from $1 C$ to $600 C\left(1 C=335 \mathrm{~mA} \mathrm{~g}^{-1}\right)$. Dashed lines depict the profiles at $1 \mathrm{C}$ immediately following the last cycle at the highest rate. e) Capacity retention at constant $60 \mathrm{C}$ and $80 \mathrm{C}$ rates for 200 cycles in a voltage window of $1-3 \mathrm{~V}$. 
a

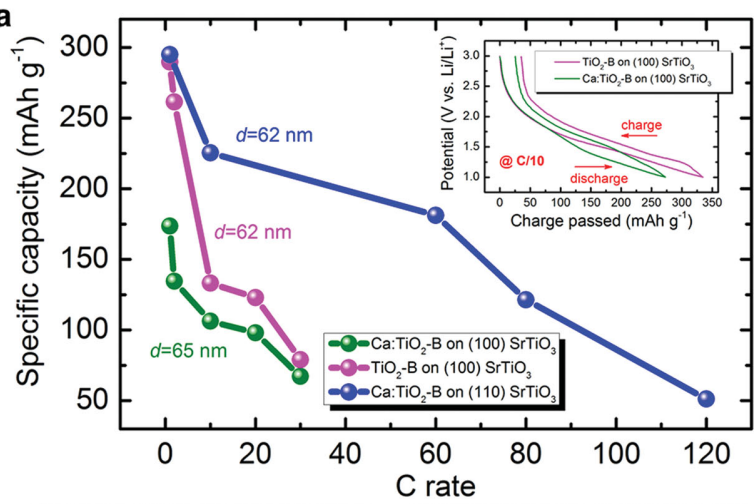

d (001) $\mathrm{Ca}: \mathrm{TiO}_{2}-\mathrm{B}$
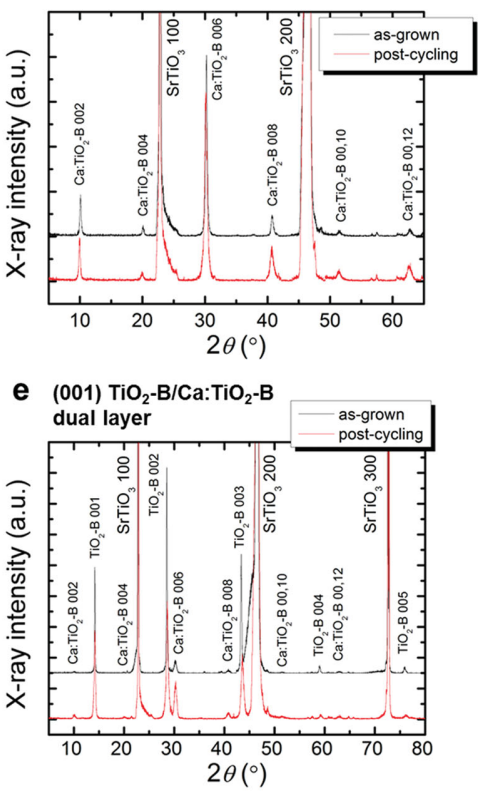

Figure 4. Rate capability comparison and structural change after cycling. a) Discharge capacity at the $20^{\text {th }}$ cycle of both $\mathrm{TiO}_{2}-\mathrm{B}$ and $\mathrm{Ca}: \mathrm{TiO}_{2}-\mathrm{B}$ with different orientation at increasing rates. Respective film thicknesses $(d)$ are labeled. Solid lines are guides for the eyes. Inset: potential profiles at the $5^{\text {th }}$ cycle of (001) $\mathrm{TiO}_{2}-\mathrm{B}$ and $\mathrm{Ca}: \mathrm{TiO}_{2}-\mathrm{B}$ films at $\mathrm{C} / 10$ rate $\left(33.5 \mathrm{~mA} \mathrm{~g}^{-1}\right)$. b,c) Before (b) and after (c) cycling structural comparison of a TiO $-\mathrm{B} / \mathrm{Ca}_{2}: \mathrm{TiO}_{2}-\mathrm{B}$ dual-layer film grown on (100) $\mathrm{SrTiO}_{3}$. A fracture at the interface is clearly seen. Such fractures were observed throughout the post-cycling film. d,e) XRD patterns before (d) and after (e) cycling of both a $\mathrm{Ca}: \mathrm{TiO}_{2}-\mathrm{B}$ film and a $\mathrm{TiO}_{2}-\mathrm{B} / \mathrm{Ca}: \mathrm{TiO}_{2}-\mathrm{B}$ dual-layer film on (100) $\mathrm{SrTiO}_{3}$.

was actually lithiated at higher rates. When the rate was lowered back to $1 C$, the capacity was immediately restored to $284 \mathrm{~mA} \mathrm{~h} \mathrm{~g}^{-1}$, showing outstanding endurance of the material under extreme conditions. The majority of the capacity occurred in the sloped regions of the voltage profiles, while the specific capacity obtained by integrating the cyclic voltammograms was almost the same regardless of the scan rate (SI: Figure S4), expressing the pseudocapacitive Faradaic behavior of Li storage in this material. The battery half-cell was continuously charged and discharged for 200 cycles at $60 \mathrm{C}$ and $80 \mathrm{C}$, as shown in Figure 3e, delivering discharge capacities of 155 and $102 \mathrm{~mA} \mathrm{~h} \mathrm{~g}^{-1}$ at the $100^{\text {th }}$ cycle, respectively. The capacity loss and the lower Coulombic efficiency in the first 10 cycles reflect the poor electrical conductivity characteristics of pure $\mathrm{Ca}: \mathrm{TiO}_{2}-\mathrm{B} \cdot{ }^{[21]}$ From cycle 10 to 200, however, the loss was only $0.1 \%$ per cycle, and the Coulombic efficiency close to 1 .

Taking advantage of the clearly defined lattice orientation, we can now experimentally demonstrate the presumed preference for $\mathrm{Li}^{+}$transport along certain crystal directions. The rate capability of $\mathrm{Ca}: \mathrm{TiO}_{2}$-B thin films grown on (110) $\mathrm{SrTiO}_{3}$ with channel openings on the surface is compared with both $\mathrm{Ca}: \mathrm{TiO}_{2}-\mathrm{B}$ and $\mathrm{TiO}_{2}$ - $\mathrm{B}$ grown on (100) $\mathrm{SrTiO}_{3}$ with channels along the $a$ - and $b$-axes running parallel to the surface. Considering the impaired electron transport in these materials, all three samples were grown to almost the same thickness in order to ensure a fair comparison. Slow cycling tests at a $C / 10$ rate-shown in the inset of Figure $4 \mathrm{a}$-were performed on the two (001) films that have in-plane $a$ - and $b$-channels, where $\mathrm{TiO}_{2}$-B and $\mathrm{Ca}: \mathrm{TiO}_{2}$ - $\mathrm{B}$ discharge to $334\left(\mathrm{Li}_{0.997} \mathrm{TiO}_{2}\right)$ and $273 \mathrm{~mA} \mathrm{~h} \mathrm{~g}^{-1}$, respectively. As the rate increases (Figure 4a), $\mathrm{TiO}_{2}$ - $\mathrm{B}$ delivers higher capacities than $\mathrm{Ca}: \mathrm{TiO}_{2}$-B at every rate, indicating that $\mathrm{Li}^{+}$transport along the out-of-plane direction is faster in $\mathrm{TiO}_{2}$-B than in $\mathrm{Ca}: \mathrm{TiO}_{2}-\mathrm{B}$, because the difference in theoretical capacity alone is unlikely to account for such discrepancy. On the other hand, the $\mathrm{Ca}: \mathrm{TiO}_{2}$-B film with exposed $a$ - and $b$-channels exhibits far superior rate capabilities to both of the above, suggesting a better efficiency of inserting and extracting $\mathrm{Li}^{+}$. The superiority becomes more and more significant with increasing rates. For example, its capacity at $60 \mathrm{C}$ is even higher than the $10 \mathrm{C}$ capacity of $\mathrm{TiO}_{2}$ - $\mathrm{B}$ and the $1 \mathrm{C}$ capacity of the same $\mathrm{Ca}: \mathrm{TiO}_{2}$-B phase in the different crystal orientation. These results suggest that $\mathrm{Li}^{+}$transport into the bulk of the material is indeed much faster in the $\mathrm{Ca}: \mathrm{TiO}_{2}$-B film on (110) $\mathrm{SrTiO}_{3}$, either because channels within the $a-b$ plane are more favorable for $\mathrm{Li}^{+}$transport than the ones along the $c$-axis, or due to certain effects associated with the polycrystalline structure and grain boundaries.

The material's response to the intensive cycling was examined by XRD and transmission electron microscopy (TEM). XRD patterns of both the $\mathrm{TiO}_{2}-\mathrm{B}$ and $\mathrm{Ca}: \mathrm{TiO}_{2}-\mathrm{B}$ structures before and after being cycled for over 40 days are essentially unchanged (Figure 4d,e). Atomic-resolution TEM analysis confirmed that all the bronze structures stayed intact without any signs of significant degradation or collapse into other $\mathrm{TiO}_{2}$ polymorphs. As an example, a post-cycling HAADF image of the inclined $\mathrm{Ca}: \mathrm{TiO}_{2}$-B structure is shown in Figure 3c. Relatively subtle changes, however, were observed by comparing the images before and after cycling in the horizontally oriented (001) films. Figure $4 \mathrm{~b}$ shows a region near the interface between $\mathrm{TiO}_{2}$ - $\mathrm{B}$ and the $\mathrm{Ca}: \mathrm{TiO}_{2}$-B template in an as-grown dual-layer film on (100) $\mathrm{SrTiO}_{3}$. A straight, inclined anatase "wall" $\sim 3 \mathrm{~nm}$ wide stems from the interface and extends to 
the surface, separating two $\mathrm{TiO}_{2}$-B grains. Upon lithiation, the anatase phase experiences a volumetric increase along the wall, while the $\mathrm{TiO}_{2}$ - $\mathrm{B}$ grain undergoes a contraction along its $c$ axis, ${ }^{[38,39]}$ and consequently creates a small fracture at the interface, as shown by the HAADF image in Figure 4c. Such fractures were seen repeatedly in the post-cycling sample along the anatase walls (SI: Figure S8). More direct proof that $\mathrm{Li}^{+}$is being inserted into the films comes from XRD, where fine scans were performed around the $\mathrm{Ca}: \mathrm{TiO}_{2}-\mathrm{B} 006$ peak and $\mathrm{TiO}_{2}-\mathrm{B}$ 001 peak on respective (001) films before and after lithiation (SI: Figure S7). Shifts in the peak positions indicate a slight increase in the $c$-axis lattice constant of $\mathrm{Ca}: \mathrm{TiO}_{2}$-B and a slight decrease in that of $\mathrm{TiO}_{2}-\mathrm{B} \cdot{ }^{[38]} \mathrm{A}$ broadening was also observed in both peaks as the inserted $\mathrm{Li}^{+}$causes local straining.

Our work provides evidence that by aligning the material to a preferred orientation, the titania-bronze structure can safely work at extremely high rates, delivering specific power of $\sim 20 \mathrm{~kW} \mathrm{~kg}^{-1}$ at $60 \mathrm{C}$ and $\sim 35 \mathrm{~kW} \mathrm{~kg}^{-1}$ at $600 \mathrm{C}$. Coupling with a cathode material that sustains ultrahigh rates, such as $\mathrm{LiFePO}_{4}{ }^{[16]}$ and its modifications, ${ }^{[1,40]}$ we anticipate that a superfast-charging full-cell may be made. Having demonstrated this waterless method to synthesize these materials, we also anticipate that many researchers will be able to fabricate high-quality crystalline $\mathrm{TiO}_{2}$-B or $\mathrm{Ca}: \mathrm{TiO}_{2}-\mathrm{B}^{[41]}$ films and devices based upon them in the near future.

\section{Experimental Section}

The $\mathrm{CaTi}_{4} \mathrm{O}_{9}$ target used to grow $\mathrm{Ca}: \mathrm{TiO}_{2}-\mathrm{B}$ thin films was made by mixing $80 \% \mathrm{TiO}_{2}$ and $20 \% \mathrm{CaO}$ powders, sintering at $1400{ }^{\circ} \mathrm{C}$, and pressed into a pellet under $10000 \mathrm{lb}$ of force $(2.205 \mathrm{lb}=1 \mathrm{~kg})$. The vacuum chamber used for PLD has a base pressure of $<10^{-7}$ Torr. A 248-nm KrF excimer laser with a pulse duration of $22 \mathrm{~ns}$ and a fluence of $\sim 3.4 \mathrm{~J} \mathrm{~cm}^{-2}$ was used for the deposition at a $10-\mathrm{Hz}$ repetition rate, and the substrate-target distance was set to $6.35 \mathrm{~cm}$. Thin films were deposited at $800{ }^{\circ} \mathrm{C}$ in an oxygen ambient of 0.05 Torr. The deposition rate was $0.01-0.02 \AA /$ pulse. Films studied in this work have thicknesses of 50-200 nm (typical deposition time of 1-4 h), which were measured by a Veeco Dektak profilometer and confirmed with TEM images. The XRD results were obtained on a Rigaku rotating-anode diffractometer using $\mathrm{Cu} \mathrm{K} \alpha$ radiation. All STEM images were captured on a JEOL $2100 \mathrm{~F}$ TEM equipped with a spherical aberration corrector. Battery half-cells (EL-CELL ECC-STD) were assembled in an argon-filled glove box (Innovative Technology Inert Lab) with $\mathrm{O}_{2}$ and $\mathrm{H}_{2} \mathrm{O}$ levels below 2 and 1 ppm, respectively, and tested at room temperature on a Princeton Applied Research VersaSTAT MC 4-channel system operating in galvanostatic mode using a lithium metal anode, non-aqueous electrolyte (1 M LiPF 6 in ethylene carbonate:dimethyl carbonate 1:1 (v/v), Merck) and a $1.55-\mathrm{mm}$-thick glass fiber separator. The assembly of the film electrode in battery cells and data acquisition protocols are detailed in the SI, Section III. To calculate specific capacity, the mass of the active material was determined from its theoretical density, measured surface area, and thickness. The mass loading of active material was $\sim 0.036 \mathrm{mg} \mathrm{cm}^{-2}$. Cycled cells were disassembled in the glove box, and post-cycling films were washed in dimethyl carbonate three times and dried in vacuum overnight before XRD and TEM studies.

\section{Supporting Information}

Supporting Information is available from the Wiley Online Library or from the author.

\section{Acknowledgements}

This work was supported by Ford Motor Company under a University Research Proposal grant, the National Science Foundation through Grants CBET-1159240 and DMR-0723032 (aberration-corrected TEM), and partially by the US Department of Energy, Office of Basic Energy Sciences, Division of Materials Sciences and Engineering under Awards DE-FG02-07ER46416 (TEM experiments).

Received: April 17, 2014

Revised: July 14, 2014

Published online: September 22, 2014

[1] B. Kang, G. Ceder, Nature 2009, 458, 190.

[2] R. Marchand, L. Brohan, M. Tournoux, Mater. Res. Bull. 1980, 15, 1129.

[3] M. Zukalova, M. Kalbac, L. Kavan, I. Exnar, M. Graetzel, Chem. Mater. 2005, 17, 1248.

[4] V. Augustyn, J. Come, M. A. Lowe, J. W. Kim, P. L. Taberna, S. H. Tolbert, H. D. Abruna, P. Simon, B. Dunn, Nat. Mater. 2013, 12, 518.

[5] A. S. Arico, P. Bruce, B. Scrosati, J. M. Tarascon, W. Van Schalkwijk, Nat. Mater. 2005, 4, 366.

[6] T. Kogure, T. Umezawa, Y. Kotani, A. Matsuda, M. Tatsumisago, T. Minami, J. Am. Ceram. Soc. 1999, 82, 3248.

[7] A. R. Armstrong, G. Armstrong, J. Canales, P. G. Bruce, Angew. Chem. Int. Ed. 2004, 43, 2286.

[8] G. Armstrong, A. R. Armstrong, J. Canales, P. G. Bruce, Chem. Commun. 2005, 2454.

[9] T. Beuvier, M. Richard-Plouet, M. Mancini-Le Granvalet, T. Brousse, O. Crosnier, L. Brohan, Inorg. Chem. 2010, 49, 8457.

[10] H. Liu, Z. Bi, X.-G. Sun, R. R. Unocic, M. P. Paranthaman, S. Dai, G. M. Brown, Adv. Mater. 2011, 23, 3450.

[11] S. Liu, H. Jia, L. Han, J. Wang, P. Gao, D. Xu, J. Yang, S. Che, Adv. Mater. 2012, 24, 3201.

[12] W. J. Zhou, L. G. Gai, P. G. Hu, J. J. Cui, X. Y. Liu, D. Z. Wang, G. H. Li, H. D. Jiang, D. Liu, H. Liu, J. Y. Wang, CrystEngComm 2011, 13, 6643.

[13] V. Etacheri, Y. Kuo, A. Van der Ven, B. M. Bartlett, J. Mater. Chem. A 2013, 1, 12028.

[14] X. Chen, S. S. Mao, Chem. Rev. 2007, 107, 2891.

[15] Z. G. Yang, D. Choi, S. Kerisit, K. M. Rosso, D. H. Wang, J. Zhang, G. Graff, J. Liu, J. Power Sources 2009, 192, 588.

[16] G. Armstrong, A. R. Armstrong, P. G. Bruce, P. Reale, B. Scrosati, Adv. Mater. 2006, 18, 2597.

[17] J. S. Chen, Y. L. Tan, C. M. Li, Y. L. Cheah, D. Y. Luan, S. Madhavi, F. Y. C. Boey, L. A. Archer, X. W. Lou, J. Am. Chem. Soc. 2010, 132, 6124.

[18] J. S. Chen, X. W. Lou, J. Power Sources 2010, 195, 2905.

[19] J. M. Feckl, K. Fominykh, M. Doblinger, D. Fattakhova-Rohlfing, T. Bein, Angew. Chem. Int. Ed. 2012, 51, 7459.

[20] X. G. Hao, B. M. Bartlett, Adv. Energy Mater. 2013, 3, 753.

[21] A. R. Armstrong, G. Armstrong, J. Canales, R. Garcia, P. G. Bruce, Adv. Mater. 2005, 17, 862.

[22] C. Wessel, L. A. Zhao, S. Urban, R. Ostermann, I. Djerdj, B. M. Smarsly, L. Q. Chen, Y. S. Hu, S. Sallard, Chem.-Eur. J. 2011, $17,775$.

[23] S. H. Liu, Z. Y. Wang, C. Yu, H. B. Wu, G. Wang, Q. Dong, J. S. Qiu, A. Eychmuller, X. W. Lou, Adv. Mater. 2013, 25, 3462.

[24] Y. Ren, Z. Liu, F. Pourpoint, A. R. Armstrong, C. P. Grey, P. G. Bruce, Angew. Chem. Int. Ed. 2012, 51, 2164.

[25] A. A. Belak, Y. Z. Wang, A. Van der Ven, Chem. Mater. 2012, 24, 2894.

[26] A. G. Dylla, G. Henkelman, K. J. Stevenson, Acc. Chem. Res. 2013, 46, 1104. 
[27] S. Pavasupree, Y. Suzuki, S. Yoshikawa, R. Kawahata, J. Solid State Chem. 2005, 178, 3110.

[28] J. P. Perdew, K. Burke, M. Ernzerhof, Phys. Rev. Lett. 1996, 77, 3865.

[29] G. Kresse, J. Hafner, Phys. Rev. B 1993, 48, 13115.

[30] P. Deak, B. Aradi, T. Frauenheim, E. Janzen, A. Gali, Phys. Rev. B 2010, 81, 153203.

[31] A. Lotnyk, S. Senz, D. Hesse, Thin Solid Films 2007, 515, 3439.

[32] M. Tournoux, R. Marchand, L. Brohan, Prog. Solid State Chem. 1986, 17, 33

[33] T. P. Feist, P. K. Davies, J. Solid State Chem. 1992, 101, 275.

[34] C. Arrouvel, S. C. Parker, M. S. Islam, Chem. Mater. 2009, 21, 4778.

[35] D. Panduwinata, J. D. Gale, J. Mater. Chem. 2009, 19, 3931.
[36] T. Okumura, T. Fukutsuka, A. Yanagihara, Y. Orikasa, H. Arai, Z. Ogumi, Y. Uchimoto, J. Mater. Chem. 2011, 21, 15369.

[37] D. C. Johnson, A. L. Prieto, J. Power Sources 2011, 196, 7736.

[38] A. R. Armstrong, C. Arrouvel, V. Gentili, S. C. Parker, M. S. Islam, P. G. Bruce, Chem. Mater. 2010, 22, 6426.

[39] M. Wagemaker, G. J. Kearley, A. A. van Well, H. Mutka, F. M. Mulder, J. Am. Chem. Soc. 2003, 125, 840.

[40] S.-i. Nishimura, G. Kobayashi, K. Ohoyama, R. Kanno, M. Yashima, A. Yamada, Nat. Mater. 2008, 7, 707.

[41] R. Ancora, M. Borsa, M. I. Marchi (Italcementi S.P.A) US20110192325 A1, 2011. 